\section{PCR-Based Method for the Construction of Gene Disruption Cassettes in Yeast}

\author{
BioTechniques 31:264-268 (August 2001)
}

An advantage of modern yeast genetics is the ease by which null mutations can be introduced into the chromosome. Different gene disruption methods have been described (6). Here, we report a new approach to construct a mutagenizing PCR-based cassette. The first step involves cloning yeast genom ic DNA into a bacterial plasmid as the method described by Rothstein (7). However, to generate the deletion and to insert a selectable genetic marker, our method does not require restriction sites within the gene. This is relevant because the lack of appropriate restriction sites often leads to difficulties in the construction of the disruption cassette. Recently, protocols based on PCR-generated DNA fragments containing the marker flanked by short sequences homologous to the genomic DNA to be deleted have been widely used (10), revealing limitations at the level of transformation efficiency. Nikawa and Kawabata (5) reported a method that also involves PCR that produces long flanking homologies increasing the transformation efficiency. However, the synthesis of the cassette comprises three steps of PCR and the addition of $T$ residues in the marker.

The method described here involves primers that are designed to amplify the whole vector, as well as the genomic DNA regions flanking the deletion (Figure 1a). This strategy requires a unique reaction of amplification with two short oligonucleotide primers and enables one to delimit the size of the deletion and of the flanking regions necessary for homologous recombination. The PCR is carried out with a DNA polymerase, which produces fragments with non-phosphorylated blunt ends. The product of amplification (Figure 1b) is ligated to a bluntended fragment containing the genetic marker. The construction obtained is linearized by restriction digestion to liberate the mutagenizing cassette (Fig-

Table 1. Disruption Cassettes of K. lactis MUP1 and MUP2 Genes

\begin{tabular}{|c|c|c|}
\hline & Cassette 1 & Cassette 2 \\
\hline Genetic marker & KanMX4 & ScURA3 \\
\hline Flanking DNA sizes (bp) & 425 and 432 & 353 and 151 \\
\hline 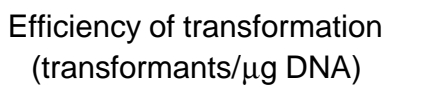 & 150 & 188 \\
\hline $\begin{array}{l}\text { Frequency of integration at the } \\
\text { correct locus }\end{array}$ & $8 / 8$ & $1 / 8$ \\
\hline
\end{tabular}

Table 2. Oligonucleotides Referred to in the Paper and Respective Positions on the Gene Sequences

\begin{tabular}{|cc|}
\hline Name & Sequence and Position of the Primers \\
\hline A & $-516\left(5^{\prime}-\right.$ ATTTTCATCATGGTGGCTC-3' $)-498$ \\
B & $+573\left(5^{\prime}-\right.$ CAGCGGCAGGCATAAACCC-3' $)+591$ \\
C & $+146\left(5^{\prime}-\right.$ GGCGAAACCCGTATCTCG-3' $)+128$ \\
D & $+242\left(5^{\prime}-\right.$ GGCTGTTGCTGCTGTTGCT-3') +260 \\
\hline
\end{tabular}

ure 1c). This method has several advantages: $(i)$ no restriction sites are needed to delimit the size of the deletion and of the flanking regions utilized for homologous recombination; (ii) a pair of short primers is used, lowering the financial cost; and (iii) the size of the flanking region needed for homologous recom bination can be precisely defined. This last aspect is particularly relevant for molecular genetics with yeast species exhibiting low rates of homologous recombination, such as Kluyveromyces lactis (3). Efficient gene targeting in $K$. lactis is indeed very difficult to achieve, and a large number of $K$. lactis transformants must be screened to find the one that carries the integration at the target locus. Stark and Milner (9) could only detect $11 \%$ correct integration when a $K$. lactis gene was disrupted. Luyten et al. (4) screened over 100 transformants to find one carrying the correct construction. Using the present method it was possible to disrupt MUP1 gene (GenBank ${ }^{\circledR}$ accession no. $\mathrm{AJ} 271895$ ) and its isogene, $M U P 2$, of $K$. lactis genome (Table 1) to obtain a double mutant mup $1 \Delta$ mup $2 \Delta$. The two cassettes were made using the genetic markers kanMX4 and ScURA3, excised from the plasmids pFA6a-kanMX4 and YDpU (2,10), respectively. Following the protocol described here, an EcoRI internal fragment of MUP1 (from nucleotide -923 to +1005 ) was subcloned in the multiple cloning site (MCS) of the bacterial plasmid pBS. The primers used to perform the PCR, A and B (Table 2), allowed a deletion of 1071 bp. To disrupt $M U P 2$, the isogene copy of $M U P 1$, a PCR fragment from nucleotide -207 to +393 was subcloned in the bacterial plasmid pGEM $^{\circledR}$-T easy (Promega, Madison, WI, USA). The primers used to make the deletion were $\mathrm{C}$ and D (Table 2). This strategy allowed a second internal deletion of 96 bp and avoided homologous recombination at the former locus.

The following procedure can be used to disrupt your favorite yeast gene:

1. Define the target yeast genomic DNA sequence that contains the region to be deleted plus the one that will constitute the flanks of the disruption cassette. This fragment can be obtained either by genomic DNA PCR or from restriction enzyme digestion of a previously cloned molecule containing the target sequence. Subsequently, resolve the reaction products by agarose gel electrophoresis. Purify the target DNA fragment using a QIAex ${ }^{\circledR}$ II gel extraction system (Qiagen, Valencia, CA, USA) and clone it into the MCS of a bacterial plasmid (e.g., pGEM-T easy, pBS).

2. Choose a pair of primers that allows the amplification of the target yeast genomic DNA regions flanking the deletion and the remainder of the bacterial plasmid. 


\section{Benchmarks}

3. Perform the PCR in a volume of $50 \mu \mathrm{L}$ that includes $20 \mathrm{ng}$ template DNA (prepared in step 1), $1 \mu \mathrm{M}$ each primer DNA (specified in step 2), 200 $\mu \mathrm{M}$ dNTPs, and 1.25 U Pfu DNA polymerase (Promega) in $1 \times P f u$ DNA polymerase reaction buffer. A preliminary step of denaturation at $95^{\circ} \mathrm{C}$ for $5 \mathrm{~min}$ is followed by 25 cycles of PCR. These PCR cycles consist of 1 min of denaturation at $95^{\circ} \mathrm{C}, 1 \mathrm{~min}$ of annealing at $0^{\circ} \mathrm{C}-5^{\circ} \mathrm{C}$ below the melting temperature $\left(\mathrm{T}_{\mathrm{m}}\right)$ of the primer with the lowest $\mathrm{T}_{\mathrm{m}}$ and $1 \mathrm{~min}$ of extension at $72^{\circ} \mathrm{C} / \mathrm{kb}$ template. After these cycles, perform a final 10-min extension step at $72^{\circ} \mathrm{C}$. Cool the samples to $4^{\circ} \mathrm{C}$ for storage.

4. Check the PCR product by agarose gel electrophoresis and purify the blunt-ended linear DNA molecule using the QIAex II gel extraction system and store at $-20^{\circ} \mathrm{C}$.

5. Obtain a blunt-ended fragment containing a genetic marker. Remove the $1.5-\mathrm{kb}$ kanMX4 cassette from the plasmid pFa6A-kanMx4 (10) using the enzymes $E c o \mathrm{RV}$ and $P v u \mathrm{II}$. Alternative markers can be used, namely ScURA3, removed from the plasmid YDpU (2) by digestion with $P v u I I$. After enzy-

a)

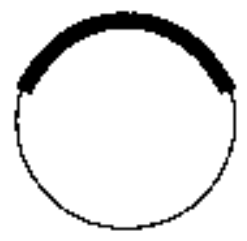

\section{If. $x$;}

Yaxal yonomic DX

b)
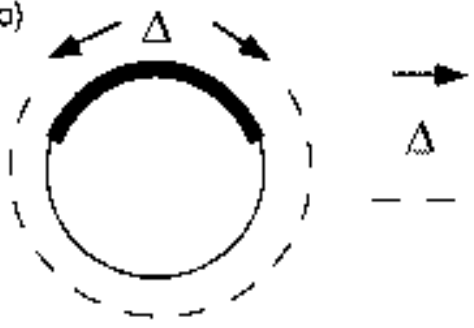

\section{5-3.primar alrentation}

A yeast genumic DVA deleted

- - PCR anplilisd fraement

(blunt add mutr-[1hosphorylak

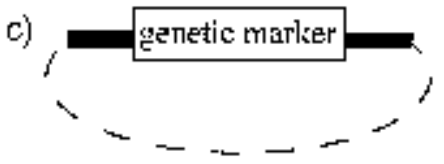

PC.K amplifïed fragrrienl (biurt and non-phosphorylated) plus

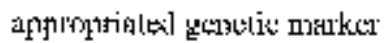
(blartl)

d)

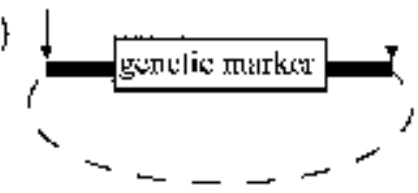

\section{Restriction digestion}

e)

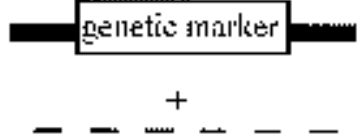

\section{Mutagonizing cascttc plus E. toli 1MA veckir}

matic digestion, check the products on an agarose gel and purify the DNA fragment containing the genetic marker using a QIAex II gel extraction system.

6. Ligate together the PCR DNA fragment from step 4 and the genetic marker from step 5 using standard methods (8).

7. Amplify the resulting vector by conventional techniques and excise the mutagenizing cassette (flanking region 1 of yeast genomic DNA genetic marker-flanking region 2 of yeast genomic DNA). Use appropriate restriction enzymes from the MCS of the bacterial plasmid.

8 . Check the products by agarose gel electrophoresis and recover the cassette using a QIAex II gel extraction system. Use $0.5 \mu \mathrm{g}$ of this DNA to transform yeast competent cells by electroporation $(25 \mu \mathrm{F}, 200 \omega, 1500 \mathrm{~V}$; Gene Pulser $^{\circledR}$; Bio-Rad Laboratories, Hercules, CA, USA) (1,3). Use selective media to obtain the yeast transformant clones (1).

9. Verify gene deletions by Southern hybridization and/or analytic PCR, using standard protocols (8).

\section{REFERENCES}

1.Ausubel, F.A., R. Brent, D. Kingston, D. Moore, J.G. Seidman, J.A. Smith, and K. Struhl. 1998. Current Protocols in Molecular Biology. John Wiley \& Sons, New York.

2.Berben, G., J. Dumont, V. Gilliquet, P.-A. Bolle, and F. Hilger. 1991. The YDp plasmids: a uniform set of vectors bearing versatile gene disruption cassettes for Saccharomyces cerevisiae. Yeast 7:475-477.

3.Bundock, P., K. Mróczek, A.A. Winkler, H.Y. Steensma, and P.J.J. Hooykaas. 1999. T-DNA from Agrobacterium tumefaciens as an efficient tool for gene targeting in Kluyveromyces lactis. Mol. Gen. Genet. 261:115-121.

4.Luyten, K., W. De Koning, I. Tesseur, M.C. Ruiz, J. Ramos, P. Cobbaert, J.M. Thevelein, and S. Hohmann. 1993. Disruption of the Kluyveromyces lactis GGSI gene causes inability to grow on glucose and fructose and is suppressed by mutations that reduce sugar uptake. Eur. J. Biochem. 217:701713.

5.Nikawa, J.-I. and M. Kawabata. 1998. PCRand ligation-mediated synthesis of marker cassettes with long flanking homology regions for gene disruption in Saccharomyces cerevisiae. Nucleic Acids Res. 26:860-861.

6.Rose, M.D. 1995. Modern and post-modern genetics in Saccharomyces cerevisiae, p. 83 88. In A.H. Rose, A.E. Wheals, and J.S. Harrison (Eds.), The Yeasts: Yeast Genetics. Acad- 


\section{Benchmarks}

emic Press, London.

7.Rothstein, R.J. 1983. One-step gene disruption in yeast. Methods Enzymol. 101:202-211.

8.Sambrook, J., E.F. Fritsch, and T. Maniatis. 1989. Molecular Cloning: A Laboratory Manual. CSH Laboratory Press, Cold Spring Harbor, NY.

9.Stark, M.J. and J.S. Milner. 1989. Cloning and analysis of the Kluyveromyces lactis TRP1 gene: a chromosomal locus flanked by genes encoding inorganic pyrophosphatase and histone H3. Yeast 5:35-50.

10.Wach, A., A. Brachat, C. Rebischung, S. Steiner, K. Pokorni, S. Heesen, and P. Philippsen. 1998. PCR-based gene targeting in Saccharomyces cerevisiae. Methods Microbiol. 26:67-81.

The work was supported by the Portuguese project PRAXIS/2/2.1/BIO/1068/ 95. Address correspondence to Dr. Margarida Casal, Centro de Ciências do Ambiente, Departamento de Biologia, Universidade do Minho, 4710-057 Braga, Portugal. e-mail: mcasal@bio.uminho.pt

Received 7 August 2000; accepted 23 April 2001.

Odília Queirós ${ }^{\mathbf{1}, 2,3}$, Margarida
Casal $^{\mathbf{1}}$, Pedro Moradas-
Ferreira $^{\mathbf{2}}$, and Cecília Leão
${ }^{\mathbf{1}}$ Universidade do Minho
Braga
${ }^{2}$ Universidade do Porto
Porto
${ }^{3}$ ISCSN
Paredes, Portugal

Paredes, Portugal

\section{High-Probability Amplification of Genomic DNA Starting from cDNA}

\author{
BioTechniques 31:268-272 (August 2001)
}

After the cDNA for a protein is cloned and sequenced, there is frequently a need to obtain the corresponding genomic DNA to analyze the gene structure and its regulation. There are several published methods designed to pursue this goal. A genomic library may be screened by either Southern blot hybridization or PCR amplification (1) using primers that are designed on the basis of the sequence of cloned cDNAs. Such primers may also be used to amplify by PCR a DNA fragment from genomic DNA extracted from cells. PCR amplification is a frequently used procedure in such studies because of its sensitivity and efficiency.

However, the interruption of exon sequences by introns could introduce a high rate of failure in PCR amplification. When the only information available is the sequence of a cloned eukaryotic cDNA, then it is difficult to predict the presence or location of introns in the sequence of the respective genomic DNAs. Methods such as inverse PCR (2) and anchor PCR (5) have been used to amplify genomic DNA, but these also suffer from the ambiguities caused by the lack of knowledge about the presence and location of introns in genomic sequences. Increasing the probability of successful amplification of genomic DNA sequences using primers based on cDNA sequences remains a problem.

Here, we describe a strategy based on an analysis of known genomic sequences that revealed a minimum length of exons in 200 genes examined that is longer than $40 \mathrm{bp}$. Therefore, the method of amplification of genomic DNA sequences developed was based on the use of two adjacent forward and two adjacent reverse primers, each 20 $\mathrm{bp}$ in length. The primers were designed on the basis of known cDNA sequences but without the knowledge of the ge-

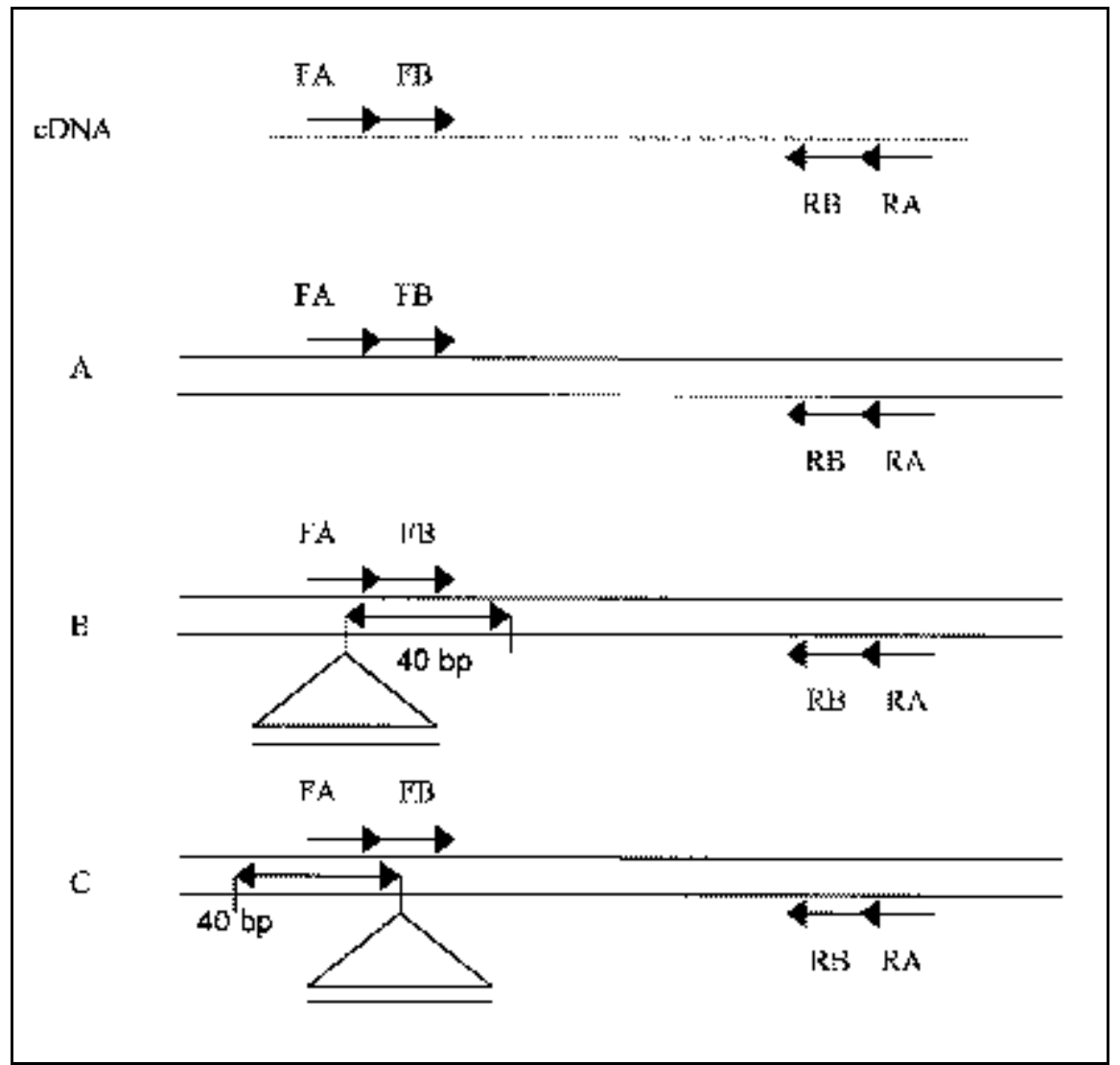

Figure 1. Diagram of the PCR primer design. FA, FB, RA, and RB represent forward $(F)$ and reverse (R) primers. FA and FB are adjacent to each other, as are RA and RB. We assume that the length of all exons is no less than $40 \mathrm{bp}$ and that the genomic DNA between them is in the range of PCR amplification (conventionally less than $5 \mathrm{kbp}$ ). There are three possible outcomes of hybridization of FA and FB to genomic DNA: (A) both FA and FB hybridize to an exon, (B) FA is interrupted by an intron, but FB is not, (C) FB is interrupted by an intron, but FA is not. Thus, there is at least one forward primer that is not interrupted by introns. For the reverse primers, RA and RB, the situation is the same as that for the forward primers. If the combinations of four adjacent primers are used to amplify genomic DNA, then we predict that at least one pair of primers will successfully amplify the genomic DNA sequence between them. 